\title{
ENTREVISTA A QUICO ROVIRA-BELETA. EL TRADUCTOR (AUDIOVISUAL) EN SU LABERINTO
}

\author{
Natalia Contreras de la Llave
}

Universidad de Alicante

Para el público que frecuenta las salas de cine, la figura del traductor para el doblaje es prácticamente invisible. Y, sin embargo, muchos de los diálogos que recordamos, algunas de las citas de cine que nos llevan de la mano por el camino de nuestra memoria cinematográfica han salido con toda probabilidad de la cabeza del traductor Quico Rovira-Beleta. Desde el padre de Luke Skywalker a la caja de bombones de Forrest Gump, desde las diatribas contra la risa de El nombre de la rosa, pasando por los pingüinos de Madagascar y los poemas de Shakespeare de Sentido y sensibilidad, hasta el universo Marvel (el doblaje de

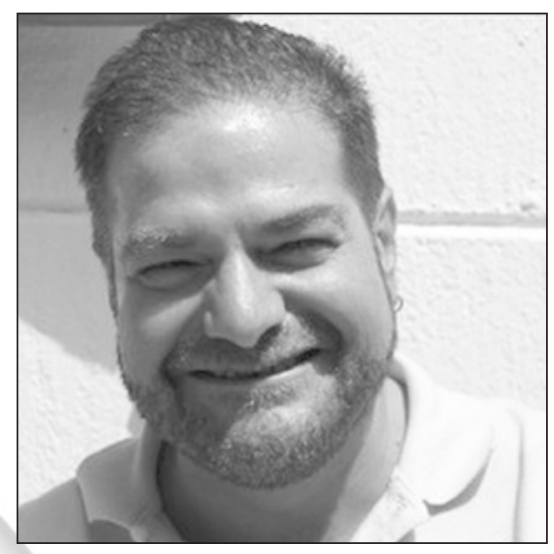
Los guardianes de la galaxia le ha proporcionado el Premio ATRAE del Público 2015), Quico Rovira-Beleta sigue traduciendo con la pasión y el rigor que merece esta profesión, enseñando a futuros profesionales del gremio los engranajes de una buena traducción audiovisual. Con casi mil películas en su haber como traductor, el hijo de Francisco Rovira-Beleta (director dos veces nominado al Óscar por Los Tarantos y El amor Brujo, respectivamente) admite que su historia personal está ligada al cine y muy especialmente a la historia del cine español, aunque reconoce su amor por la palabra más que por la imagen. Vale la pena descubrir qué hay en la trastienda de esos doblajes cinematográficos en la voz de alguien que lleva treinta años en el oficio, que sabe cómo empezó todo y cómo ha evolucionado, que responde a los detractores del doblaje al mismo tiempo que respeta profundamente la versión original. Alguien sin miedo a guiarte por los entresijos del mundo de la traducción abordando la complejidad de una tarea de enorme repercusión social.

Hola Quico, tú empezaste a traducir en 1985. Quería comenzar preguntándote cómo llegaste a esta profesión.

Pues mira, yo soy biólogo, no traductor. Yo era biólogo, me especialicé en arañas y estuve tres años intentando trabajar como aracnólogo, pero era imposible. Como siempre se me han 
dado muy bien los idiomas - hablo unos cuantos - mi padre, que era director de cine, me dijo: "Oye, yo llevo las películas a doblar a Sonoblok —un estudio de Barcelona-, ya que hablas idiomas ¿por qué no haces una prueba?". Así que fui, hice una prueba y me cogieron. $Y$ de esto hace treinta años.

\section{Vaya, pues de las arañas a la traducción de películas hay una gran distancia.}

Sí, es verdad, pero yo siempre he tenido un lema: si no estás haciendo lo que te gusta, haz que te guste lo que haces. Y a mí me encanta traducir películas, claro; si no me gustara no habría aguantado treinta años. Y las arañas están aparcadas ipara cuando me jubile! Ya lo tengo previsto, tengo mi terrario... Pero de momento no, porque no puedo dedicarles tiempo. Y volviendo al principio, es verdad que mi padre me llevó, pero si yo no hubiera valido no me habrían cogido, por supuesto.

La primera película que me dieron fue Rocky IV, que era complicadísima, con periodistas hablando todos a la vez y tuve que traducir y adaptar ${ }^{1}$, las dos cosas, y eso fue un auténtico reto. Luego hice El secreto de la pirámide, después El nombre de la rosa y ya empezaron a darme películas cada vez más importantes y así llevo cerca de mil.

\section{¿...Mil?}

Contando películas y capítulos de series. Si cuentas las series como una sola cosa, entonces llevo alrededor de setecientas. Que no está mal.

Pues no, de hecho yo tengo una lista muy larga de películas importantes. Cito unas cuantas: Toy Story, Forrest Gump, El nombre de la rosa, Star Wars, Madagascar, De ratones y hombres, todas las de Marvel... Se suele decir que hay muchas manos que afectan al producto final, incluidas las condiciones estrictas de las productoras americanas. ¿Qué te resulta más difícil en este aspecto? ¿Cómo afecta al resultado final de traducción de una película?

Mira, una de las cosas que aprendes cuando eres traductor audiovisual a diferencia de cuando eres traductor técnico, es que el traductor técnico como mucho tiene un supervisor que le revisa los textos. Cuando eres traductor literario tienes un editor, que a veces tampoco se entera mucho, con lo cual... Y cuando eres un traductor audiovisual, el cliente puede ser como un editor, que puede acertar o no acertar pero el que va detrás de ti, que es el adaptador, sabe tanto o más que tú, por lo tanto lo primero que aprendes siendo traductor audiovisual es a ser humilde, porque te van a tocar tu traducción seguro. Porque si tú solo has hecho la traducción, no has hecho el ajuste, el ajustador lo tiene que encajar en la boca y va a cambiar todo lo que haga falta. Hay una solución, que es dejarlo pre-adaptado, pero yo estoy en contra, porque a él le pagan por adaptar y tú no vas a hacer un trabajo por el que no te pagan para facilitárselo a él. Pero cuando has conseguido una frase que te ha quedado redonda, un juego de palabras o algo así que era difícil, trato de ajustarla lo

1 "El adaptador comienza su trabajo basándose en la traducción literal de los diálogos, adaptando a cada uno de los personajes las frases que le correspondan, guardando una métrica y procurando que los movimientos de los labios coincidan con las palabras que está pronunciando, es decir, que haya una buena sincronía, para ello el adaptador tiene en cuenta las labiales (las letras B-P-M), así como los gestos del personaje". De http://www. eldoblaje.com/proceso/adaptacion.htm Normalmente, el trabajo de traducción y el de adaptación lo hacen personas diferentes. 
más posible para que el adaptador lo pueda encajar. Y si tiene que encontrar una solución nueva puede estar un día entero, porque a mí me ha pasado eso de pasarme un día entero pensando una solución buena.

\section{¿Hay correctores en el proceso, también?}

En catalán sí, en castellano no. En castellano tenemos el traductor y el adaptador. Y luego si la película es muy importante viene un supervisor. Que a veces sabe mucho y a veces no tanto, pero las ideas que aportan siempre son interesantes incluso aunque sean equivocadas, porque te abren los ojos y te dan pie a la solución buena, porque entiendes de repente lo que quiere decir aunque no te lo sepa explicar. Si te dicen "es que en inglés usamos tal cosa" entonces tú propones lo que eso te sugiere. Hay supervisores buenísimos y hay supervisores no tan buenos (pero no diré nombres) y después del supervisor ya viene el cliente de aquí, que sería la distribuidora, que también aporta sus ideas y es como el editor, que a veces son acertadas y a veces no. Pero es el que manda. Si el distribuidor de cine dice que esto se llama así, por mucho que tú como traductor o traductora digas que eso no debería ser así, ellos te van a decir "ya, pero es que vende más." El márketing manda siempre y eso es lo que pasa con los títulos de las películas, que no los ponemos nosotros, a veces incluso con expresiones que tú habías puesto, pero la cambian para el título. Y luego está el productor, que normalmente se mete poco, a no ser que se trate de una de esas películas importantísimas, que entonces pueden pedirte que les mandes toda tu traducción reconvertida al inglés para que ellos puedan comparar con lo que ellos habían hecho.

\section{Ese proceso de reconvertir al inglés parece muy complejo...}

Sí, es muy complicado, eso me ha pasado con todas las de Star Wars y con muchas películas. Por ejemplo, con Gran Hotel Budapest, que la hizo Llurba², tuvo que hacer toda la copia en inglés para Wes Anderson. Esto me ha pasado a mí en algunas. Pero claro, yo cuando hago la traducción inversa no sé quién se la va a ver, pero seguro que es alguien importante porque si no, no te la piden. Y recuerdo una anécdota de una película que se llamaba Funny people (Hazme reír), que era sobre un cómico de monólogos, del tipo El club de la comedia, pero que era un amargado y entonces todo el humor tenía un fondo muy triste, muy amargo, así que tenías que hacer reír, pero tenía que notarse ese fondo. Quizá es una de las traducciones más difíciles que he hecho. Y yo mismo notaba que me faltaba ese humor, así que le propuse a la distribuidora que buscaran un cómico que le diera un repaso. Porque claro, yo tengo mucho sentido del humor y soy bastante ingenioso, pero hasta cierto punto, ya que ese no es mi trabajo habitual. Y cogieron a Santi Millán, que había sido actor de La Cubana (y ahora es el guapo de la televisión) y lo hizo muy bien, para mi gusto lo bordó. Y entonces me pidieron hacer la traducción inversa. Y claro, hacer la traducción inversa de tu traducción es una cosa, pero hacerla de los chistes que otra persona te ha cambiado y explicar esos chistes en inglés...Y recuerdo un caso clarísimo: yo había dicho "tu habitación parece una leonera" y él había corregido "tu habitación parece la madriguera de Chewbacca" (en referencia a Star Wars). Y me contestaron: "No entendemos por qué Chewbacca tiene que ser desordenado". Así que les explicas que Chewbacca es como un león grandote y que en España usamos la palabra "leonera" para decir que está hecho un desastre, y como

2 Josep Llurba Naval es uno de los traductores audiovisuales, junto con Rovira-Beleta, más conocidos. Traduce al castellano y al catalán. http://www.llurba.com/ 
Chewbacca es como un león grandote la gente enseguida va a asociar la idea, aunque él no sea desordenado y no queramos ofender a nadie... Bueno, hay que poner muchísimas explicaciones. Pero al final lo aceptaron. Y en eso consiste la traducción inversa.

\section{De todos los aspectos que entrañan dificultad en las traducciones (humor, referentes culturales...) ¿Cuál consideras más difícil?}

Los juegos de palabras. Y tengo un ejemplo de Los pingüinos de Madagascar, una película bastante reciente, en cuya versión original el personaje incorporaba a las frases el nombre de un actor famoso. Por ejemplo, llamaba a un pulpo porque había detenido a los pingüinos y para decirle "cógelos y enciérralos" le decía "Nicholas cage them"3. Y ahora en español cómo haces esto... La primera orden que tuve fue hacer lo mismo con actores españoles, entonces yo dije "Mario, a sus casas" o "Belén, rueda hasta allí", y conseguí hacerlas todas, que eran 18. Y después de haberlas trabajado tanto llegó una orden de no poner nombres de actores porque podrían pedir derechos. Así que no se hizo. Al autor de la traducción al catalán se le ocurrió hacerlo solo rimadas, para no usar los nombres de los actores, como "¡Paula, a su jaula!" y cosas así, que eran muy divertidas. Pero al final nos lo tumbaron también y finalmente dice "Nicholas, enciérralos", que pierde toda la gracia. Ahí es donde el cliente mete mano, pero en este caso yo creo que se equivoca.

\section{Tú ganaste un premio de $\operatorname{ATRAE}^{4}$ por los subtítulos de Los Miserables...}

Y este año he ganado el Premio del Público ${ }^{5}$ por Los Guardianes de la Galaxia, que es la primera vez que se hace. Es gracioso porque en la primera edición de los premios gané por los subtítulos, en la segunda edición estuve nominado por Django y en la tercera edición estaba nominado por Los Guardianes de la Galaxia y gané el Premio del Público. Y ha ganado Llurba por Gran Hotel Budapest, que es fantástica. A ver, a mí Los Guardianes de la Galaxia me encanta porque es Marvel, pero Gran Hotel Budapest es una obra maestra. Y entiendo que lo haya ganado él. Lo que no me esperaba es que el público votara Los Guardianes de la Galaxia. Pero claro, el público es muy amplio y por mucho que les digas que voten a la mejor traducida, ellos votan a la que más les ha gustado o les haya entretenido, y Los Guardianes... es muy entretenida. Así que bueno, no me puedo quejar de las tres ediciones de los premios.

Te lo comentaba porque tú has traducido los subtítulos en rima, lo cual es muy difícil por las limitaciones que suponen los subtítulos en cuanto a caracteres y demás.

Rimados y cantables. Es decir, que midieran lo mismo que en inglés para que se pudieran cantar. Como si se hubieran doblado, pero sin doblar. Esto trajo mucha polémica porque para hacer esto hay que cambiar el original, para conseguir la rima. Y perdona que te cuente esta anécdota que suelo contar, pero tengo un sobrino que fue a ver la película y me dijo "¡Decían darkness y tú has traducido noche! ¿Por qué no has puesto oscuridad?" ¡Pues porque está rimado! (risas). Sí, fue un trabajo muy duro.

3 Juego de palabras con el actor Nicholas Cage y el significado del verbo to cage (enjaular).

4 ATRAE Asociación de Traducción y Adaptación Audiovisual de España http://www.atrae.org/

5 Premio del Público también de ATRAE. 
Has traducido muchas películas que están a medio camino entre la literatura y el cine (De ratones y hombres, Master and commander, Sentido y sensibilidad, La casa de los espíritus...) ¿Cómo afrontas este tipo de traducciones?

Mira, yo soy un apasionado de la ciencia ficción y del terror, pero las obras clásicas me encantan. De hecho, con Sentido y sensibilidad, hay un club de seguidoras de Jane Austen que me localizaron solo para felicitarme, porque había un fragmento de un poema de Shakespeare y según ellas era la mejor traducción que habían encontrado nunca de ese poema, y eso me llenó un montón. Porque hay grandes traducciones de Shakespeare, claro, pero no riman, porque saben que si riman pierden parte de su poesía, y como lo mío era un trozo muy pequeñito se ve que quedó bien. También hice Lo que queda del día y son obras que son todo un reto porque hay que ser muy cuidadoso con el lenguaje.

\section{¿Te lees la novela original y la traducción que haya de la misma, incluso?}

Sí, me leo la traducción. Tengo las dos versiones, normalmente. Mira, yo tengo una costumbre que me enseñó un traductor de catalán que se llama Lluís Comes. Yo cuando me llegaba la traducción de una de estas películas inmediatamente me compraba la novela, como El nombre de la rosa, por ejemplo (bueno, en este caso ya tenía la novela), en italiano y en español. O, si no la encontraba, por lo menos la compraba en español. Hasta que él me aconsejó que hablara con la editorial, porque en cuanto les dices que vas a trabajar en una película sobre el libro, te facilitan todo lo que quieras. A ellos les interesa que tú estés agradecido a la editorial, porque a lo mejor un día te entrevistan y dices "mira, gracias a la editorial X...". Así lo he hecho con Eragon, con La edad de la inocencia... La primera vez que lo hice fue con Lo que queda del día, que no se llamaba así la novela sino Los restos del día. Y también la pedí con una película que era para jóvenes que se llamaba Así me gusta (I like it like that), con Erin Brockovich... Desde entonces siempre intento pedir la novela a las editoriales.

\section{¿Alguna vez te has puesto en contacto con los/las autores/as?}

Yo no, pero me han puesto en contacto. Y con el autor muy pocas veces, pero con el traductor sí, porque de todos los temas de derechos ya se ha encargado la distribuidora y tú solo haces tu trabajo de traducción, así que el autor original me interesa menos que el traductor de la novela. Sobre todo, porque cuando yo me encuentro con un problema me gusta saber cómo ha llegado el traductor de la novela a encontrar su solución.

Dice el escritor Claudio Magris que "el traductor es un coautor". ¿Tú te sientes coautor? En algunos momentos sí. De hecho, tenemos derechos de autor. Pero depende de la película. Nunca te puedes considerar autor, pero al menos en la traducción de cine (no sé si en literatura pasará igual, nunca he traducido literatura), tu traducción de una película es la única traducción que puede haber. Y durante 10 años nadie puede hacer otra traducción de esa película. Después, a los 10 años ya se puede hacer un redoblaje. Así que dadas estas circunstancias, sí te sientes autor ya que lo que va a ver todo el mundo es tu obra. En cambio, con los subtítulos no. De hecho, estamos luchando para que tengan los mismos derechos que el doblaje. De las asociaciones de derechos de autor, hay una que se llama DAMA que ya paga derechos de autor por subtitulación, pero la SGAE no, y estamos luchando para eso. 


\section{Tú que llevas tanto tiempo en la profesión ¿cómo crees que ha evolucionado el trabajo? Desde el tipo de traducciones, la forma de hacer el trabajo...}

Todo, todo es distinto. Mira, yo empecé sin ordenador ¡con máquina de escribir! (risas) es que tengo muchos años... ¡Son treinta años dedicado a esto! Y con papel carbón para hacer las copias... Luego ya llegó el primer PC, que me costó un millón de pesetas en aquella época, fíjate, y ahora valen 200 euros... Y no podíamos tener la imagen. Así que te daban el guion en papel, te ibas al estudio, te veías toda la película seguida y te ibas a casa a recordar todo lo que habías visto para seguir traduciendo porque la imagen no podía salir del estudio. Posteriormente, cuando ya tenías la traducción llena de dudas, donde tenías apuntado "ver imagen" por todas partes, volvías al estudio y volvías a ver la película, esta vez en moviola — tirando hacia delante y hacia atrás- e ibas anotando todas las dudas que tenías - por poner un ejemplo, si decía "glasses" anotabas si se refería a vasos o a gafas-. Una vez hecho eso, volvías a casa, lo pasabas a limpio y lo entregabas. Es decir, era un proceso en el que era normal tardar dos semanas y media o tres semanas en traducir una película. Luego llegó el Beta y después el VHS, que al principio tampoco podías llevártelos a casa, pero era más rápido porque podías pararlo e ir adelante y atrás. Luego nos dejaron llevar los vídeos a casa y ahora nos la mandan por internet, bueno, llena de protecciones, de marcas de agua, con tu nombre para evitar la piratería, etc. La diferencia es que ahora tienes una semana y antes tenías casi un mes. Y además ahora tenemos un problema que antes no teníamos. Antes hacías un guion de una película y ese guion era el definitivo, pero ahora no. Porque en aquella época, la película se estrenaba en España cuando ya llevaba un año en Estados Unidos, en cambio hoy en día las fechas de estreno coinciden a nivel mundial para evitar la piratería. Esto significa que si tienes que esperar a estar cerca de la fecha de estreno para empezar a traducir no llegas a tiempo, así que lo que hacen es enviarte los guiones mientras están rodando la película —lo que llamamos guiones preliminares-. Total, que de una película puedes acabar haciendo cinco preliminares, y en cada uno quitas cosas y añades cosas. Y a partir del preliminar 3, se empieza a doblar porque, claro, las diferencias entre el guion preliminar 1 y el final pueden ser muchísimas y no puedes gastar dinero convocando a los actores y haciéndoles doblar cosas que luego van a la basura. Y es una manera de trabajar mucho más complicada, porque ahora una película la traduces en una semana, pero la película te dura un mes y medio, por todas las versiones que te van llegando. Y en ese mes y medio ya estás con otro trabajo. Por ejemplo, ahora estoy con tres películas a la vez, porque estoy traduciendo una por primera vez, pero tengo la revisión de dos, con lo cual se atrasa todo, todos te piden las cosas para ya... Ahora estoy traduciendo un videojuego, que yo no lo suelo hacer (y espero no hacerlo nunca más) porque yo hago cine, soy de los pocos traductores que puede permitirse hacer solo cine. Yo se lo decía a los alumnos, hoy en día es muy difícil dedicarse solo a la traducción audiovisual y dentro de ella, solo al cine. Tienes que abrirte, tienes que hacer cine, televisión, accesibilidad y multimedia. O [traducción] audiovisual, jurídica y técnica, para que te llegue el dinero. Yo, por suerte, llevo muchos años y mis tarifas no son las de alguien que empieza... Tampoco son mucho más altas, pero tengo la ventaja de hacer una película detrás de otra.

En lo que se refiere a videojuegos, yo nunca lo había hecho, pero este... Ay, es que no puedo hablar mucho... 


\section{¿Es un secreto? ¿Hay contrato de confidencialidad?}

Bueno, yo siempre estoy firmando estos contratos, para no decir nada. Y tanto Marvel como Lucas Films son sagas que solo las llevo yo. Y si sale un videojuego de estas sagas solo la puedo hacer yo. Y me han dado una lista de diálogos sin contexto y esto no me había pasado nunca, no es que no tenga imagen es que no tengo ni guion. Así que hablando en el congreso con uno de los chicos que trabaja en esto me decía que ese era el pan de cada día en ese ámbito, así que espero volver pronto a mi trabajo. También he hecho televisión, la serie Star Wars Rebels, que como pertenecía a la misma saga tenía que hacerla yo.

Quería preguntarte sobre ese cliché que dice que no sabemos idiomas por el hecho de ver todas las películas dobladas, que el doblaje es una herencia franquista... $O$ incluso las recomendaciones de los críticos en prensa que advierten que no veamos la versión doblada. ¿Tú qué opinas de todo eso?

Bueno, aquí hay mucho que discutir. Primero, los defensores del doblaje no están en contra de los subtítulos, mientras que los defensores de los subtítulos sí están en contra del doblaje, lo cual es una lucha injusta. Es verdad que para los de los subtítulos también es injusta porque hay muchas más salas de cine doblado que de cine subtitulado. Por otro lado, también es verdad que el doblaje desvirtúa la película porque te cargas la banda sonora original y pones unos diálogos nuevos. Todo eso es verdad y es indiscutible, pero a una persona ciega dile cómo puede ir a ver una película subtitulada. O sabe el idioma original o no puede ir al cine, es decir que el doblaje cumple una función práctica de la que carecen los subtítulos. Segundo, en el doblaje se pone todo lo que se dice en la película, en los subtítulos se pone solo un 70 por ciento, y si la película es de Woody Allen un 50 por ciento, porque hablan tan rápido que no te da tiempo. Los subtítulos son muy limitados. Tercero, los idiomas se saben en los países porque se aprenden, no porque se vean películas. Y la prueba es que en Bulgaria, por ejemplo, no doblan solo subtitulan, y los búlgaros no saben más inglés que los españoles. En Rumanía en cambio sí, pero allí tienen una facilidad brutal para los idiomas, es una lengua latina rodeada de países eslavos dominados por los rusos durante muchos años y están muy acostumbrados a los idiomas. Hace poco, estaba en Transilvania y me encontré con una camarera que hablaba inglés perfecto y le pregunté "¿Cómo es que hablas tan bien?" y me contestó: "Es que veo cine subtitulado" y yo le dije: "Perdona, aquel señor de allí ve el cine igual que tú y habla fatal el inglés". Es decir, si tú tienes interés es otra cosa. Lo curioso es que sepas inglés y no sepas coreano, que también tiene películas subtituladas, y eso es porque no te interesa. Si quieres aprender inglés claro que ayudan los subtítulos más que el doblaje, pero no se aprende inglés gracias al cine subtitulado, el inglés se mejora gracias al subtitulado. Y eso de que es franquista no es verdad, empezó en el año 30 y empezó en Estados Unidos, no en España. Ellos empezaron filmando las películas en varios idiomas y cuando vieron que era carísimo y que no les salía a cuenta decidieron empezar a doblar. Y eso fue en la Segunda República. Más tarde, es verdad que Franco lo aprovechó con la censura para manipular, eso es evidente. Mi padre, que fue director de cine, hubo una película que no llegó a estrenar nunca iy presentó 7 guiones! Y se los tumbaron los siete. A pesar de que cambió todos los escenarios: en uno eran unos terroristas vascos y se lo tumbaron, claro; luego eran franceses, también se la tumbaron, luego unos italianos... Y así que no la hizo, y ahora tengo una sobrina que está haciendo un documental sobre mi padre y querría hacer la película que mi padre nunca pudo hacer, que es una cosa muy bonita... 
Me gustaría preguntarte de qué manera el trabajo de tu padre ha influido en ti y en tu manera de ver el cine.

Creo que ha influido a nivel mental, a nivel personal... A mi padre, cuando yo era muy joven, le hubiera gustado que me metiera en el cine, pero a mi madre no le parecía nada bien, porque el cine es muy sufrido, y más en aquella época. Para que te hagas una idea, mi padre estuvo nominado al Óscar de Hollywood por Los tarantos y se tuvo que pagar el viaje. Imagínate, en aquel momento el Estado no daba ni un duro. Es decir, un año teníamos un millón de pesetas, que en aquel momento era muchísimo, y al año siguiente mi padre no tenía trabajo. Es decir, era muy duro y mi madre no quiso que me dedicara a esto. Y mi padre entonces dijo "pues si no eres director de cine tienes que ser literato" - porque me gustaba mucho la literatura-. Y yo decidí ser biólogo. Que no digo que fuera un disgusto, pero no les hizo mucha gracia. Y curiosamente, las circunstancias de la vida me han llevado al cine, así que cuando mi padre vio que estaba otra vez en el cine, me dijo que me fuera a ayudarle, pero no quise, me gustaba más la lengua que las imágenes.

\section{¿No has estado tentado nunca de probar a hacer cine?}

Sí, pero no lo suficiente para dejarlo todo. Es algo que o notas que te sale muy de dentro o no lo haces. Sí, tengo ideas y he escrito guiones... Pero lo que me gusta es eso, escribir, no me imagino detrás de una cámara. Mi sobrina lo ve todo como lo veía mi padre, todo lo está encuadrando. Una vez colaboré con ella para un concurso de un anuncio de ginebra, en el que yo hacía de actor y de narrador. No ganó, pero fue muy bonito porque veías que estaba muy bien dirigido, ella veía los planos y eso yo no lo he tenido nunca...jLo siento, papá! Y él lo sabía, que yo podía escribirles los guiones que quisiera, pero la imagen no es lo mismo.

He leído en alguna parte que crees que lo más importante para un traductor audiovisual es conocer el lenguaje coloquial, que en realidad está muy relacionado con el conocimiento del contexto cultural de la lengua meta. Tú que eres profesor en el máster de la $\mathrm{UAB}^{6}{ }$ ¿No crees que en la formación de la traducción no se le está dando la relevancia que merece a la dimensión cultural de un idioma?

Mira, lo que sí he observado es que así como un traductor "prehistórico" está perdido si no está al día del lenguaje coloquial y solo podrá hacer clásicos de cine, estoy encontrándome con una juventud falta de cultura "antigua". Es decir, que haya alguien que te diga "no, colega solo quiere decir amigo", como me ha pasado hace poco con unos alumnos, y el hecho de que no sepan que toda la vida ha querido decir compañero de trabajo denota una gran falta de cultura. Y ya que nosotros tenemos que tener cuidado de no dar la nota cuando estamos traduciendo un lenguaje juvenil y coloquial, y estar atentos a que no parezcan jóvenes de los años 50 , ellos tienen que entender que si quieren ser traductores tienen que coger un texto en inglés y saberlo convertir al castellano de la época que corresponde a ese texto en inglés. Y si no tienen esa base, van a tener que documentarse el triple para poder hacer un texto que a nosotros nos sale solo. Mira, mi mujer, que es vallisoletana y habla un castellano muy bonito, es la reina de los refranes, sabe muchísimos como "arrieritos somos y en el camino

6 Máster en Traducción Audiovisual de la Universidad Autónoma de Barcelona. http://www.uab.cat/web/ postgrado/master-en-traduccion-audiovisual/informacion-general-1206597472083.html/param1-1536_es/param2-2002/

Quaderns, 10 (2015), pp. 49-57 
nos encontraremos", etc... Que muchos de estos jóvenes no sabrían qué quiere decir y para mí eso es triste. El fomento de la cultura tradicional no se puede perder. ¿Cuántos de esos chavales han leído a Cervantes? Pues aquí hay algún problema. En la universidad hay algún problema, y es curioso que te lo diga alguien que es profesional y no académico. Es verdad que cuando tú estás todo el día trabajando con el idioma lo tienes muy fresco, y la ventaja de un traductor es que acabas sabiendo un poco de todo y un mucho de nada... Pero sabes un poquito de todo, con lo cual si te toca un clásico sabes a qué fuentes recurrir y si te toca una película de raperos sabes a qué fuentes recurrir. Así que de los jóvenes me da miedo que las de raperos las hagan perfectas (y seguramente mejor que yo) y las clásicas les cuesten. Mira, yo a mis alumnos les pongo unas normas, las normas del traductor audiovisual las llamo (inventadas por mí). Siempre les explico la norma del 7, que significa que si tú te encuentras en una película un juego de palabras, un lenguaje clásico, algo de humor, algo enrevesado que digamos que en inglés es de un nivel 7 (en una escala de 10), tu traducción no puede bajar de 6 porque entonces estás desvirtuando la original. Eso en el doblaje, porque en subtítulos sí puede ser que no puedas hacer nada y tengas que dar una traducción literal para que no te digan luego nada, porque la gente que cree que sabe inglés es la peor que hay (risas). Es decir, volviendo a los niveles, tú no puedes traducir una película de corte clásico donde el nivel es muy culto y bajar el registro a un nivel más bajo, porque te estás cargando la película. O al revés, una película de raperos con un nivel 8 de argot y que lo traduzcas como si fueran de colegio de curas.

Y todo eso creo que se está perdiendo y hay que fomentarlo, hay que fomentar el estudio profundo del castellano, y te lo dice un catalán. Decidí traducir solo al castellano para no mezclar los idiomas, pero el catalán me encanta, como todas las lenguas.

\section{Para terminar ¿Cómo ves el futuro de la traducción audiovisual?}

Yo creo que podemos estar tranquilos, porque por fortuna el mundo audiovisual está en plena expansión, cada vez hay más productos audiovisuales, y vamos a seguir teniendo necesidad de traducir todos esos productos. Y hoy por hoy, aún no se ha inventado un traductor automático que funcione para el mundo audiovisual. Es un trabajo que necesita de la mano humana, y que espero que siga así muchos, muchos años. 
